\title{
Memory under anesthesia: Evidence for response suppression
}

\author{
ALAN S. BROWN, MICHAEL R. BEST, and DAVID B. MITCHELL \\ Southern Methodist University, Dallas, Texas \\ and \\ LLOYD C. HAGGARD \\ HCA Medical Center, Plano, Texas
}

\begin{abstract}
The present study evaluated implicit and explicit memory for auditory stimuli in 10 surgical patients. Anesthetized subjects heard sentences that contained low-frequency versions of homophones and infrequent category exemplars. During the postoperative test, subjects (a) produced sentences using the homophones and (b) generated exemplars from conceptual categories. Multiply primed items were generated less often on the test than were singly primed or new (control) items. This outcome suggests the conditioned suppression of information experienced during anesthesia, establishing a possible experimental analogue of clinical repression.
\end{abstract}

For an experience to be retrieved from memory, it is often assumed that at least some aspect of this memory must be conscious. We now know, however, that both basic (i.e., motor) and more complex (i.e., verbal) information can be retrieved without access to conscious awareness. Such processes have been recently classified as procedural/implicit memory, to distinguish them from the conscious memory systems known collectively as declarative/explicit memory (Graf \& Schacter, 1985). The two common subtypes of explicit memory are episodic, which involves an autobiographical record of daily experiences, and semantic, which is the encyclopedic store of world knowledge that exists independently of an awareness of the original source (Tulving, 1985; Tulving \& Schacter, 1990).

There are at present two traditions of evidence for unconscious memory processes. One, popularized initially by Freud, emphasizes reduced access to traumatic or emotional experiences, a process known by psychoanalysts as repression (Erdelyi \& Goldberg, 1979; Freud, 1901/ 1960). A second, noted more recently, emphasizes a facilitation of responsivity to test stimuli not consciously perceived during input (Schacter, 1987).

Within this general context, there exist reports of patients who claim to remember certain words or phrases spoken by the operating-room staff while the patients were anesthetized. Some of these experiences are consciously recalled, probably because of an inadequate anesthesia state (Kihlstrom \& Schacter, 1990). However, most are revealed indirectly. For instance, a patient may have a

\footnotetext{
This research was presented at the 1990 American Psychological As sociation Convention in Boston. We wish to thank Anne Cunningham for her assistance in producing the stimulus tapes and conducting the phone interview tests. Requests for reprints should be sent to A. S. Brown, Department of Psychology, Southern Methodist University, Dallas, TX 75275.
}

difficult time recovering from surgery or suffer severe postoperative mood difficulties because of a careless comment made during the operation. This may not be consciously recalled but be verified later by operating-room staff (Kihlstrom \& Schacter, 1990).

Several investigators have attempted to verify this anecdotally reported implicit memory phenomenon through controlled experimentation. This research usually involves presenting information to the patient while he/she is anesthetized and then administering a postoperative test. Unfortunately, these studies have not yielded clear and replicable evidence of memory for events under anesthesia (Bennett, 1988; Kihlstrom \& Schacter, 1990; Trustman, Dubovsky, \& Titley, 1977).

The present study evaluates memory for auditory events during surgery. We used a postoperative implicit memory test and attempted to bias subjects' responses on this test by auditory information presented intraoperatively. Sentences containing the low-frequency version of certain homophones, as well as relatively infrequent category exemplars paired with their category name, were presented. During the postoperative test, subjects were required to (a) produce sentences using the homophones and (b) generate three exemplars from a number of conceptual categories. Memory for information presented during anesthesia should be revealed through higher incidence of primed as compared with nonprimed responses on the postoperative test.

\section{METHOD}

\footnotetext{
Subjects

Ten patients ( 4 male, 6 female) who were to undergo nasal or sinus surgery volunteered to participate in the investigation. The surgery was performed at the HCA Medical Center of Plano, Texas. Prior to participation, each subject was fully informed about the experimental procedures and signed a consent form.
} 


\section{Stimulus Materials}

The stimuli consisted of nine homophones and nine category exemplars. For the homophones (e.g., week/weak), the less frequently spelled version (week) was implied by a sentence that biased this particular meaning (e.g., "seven days make a WEEK") (Eich, 1984). The remaining homophone pairs, with the less-frequent version listed first, were: poll/pole, hymn/him, brake/break, sea/see, knight/night, kernel/colonel, beet/beat, ferry/fairy. The category exemplars were the fifth most frequent normative response to each of nine different conceptual categories (Battig \& Montague, 1969): animal-LION, clothing-BLOUSE, body partFOOT, vegetable-POTATO, military title-CAPTAIN, relative-BROTHER, metal-ALUMINUM, fruit-PEACH, and furniture-DESK. Both the homophone and conceptual materials were randomly divided into three sets (A, B, and C), with three homophones and three category exemplars per set. This enabled each item to serve in each of three presentation conditions across subjects.

\section{Anesthesis}

No preoperative drugs were given to the patients. Anesthesia induction was accomplished by the intravenous administration of 50-100 $\mu \mathrm{g}$ of Fentanyl (a narcotic) and 300-400 mg of sodium pentothal (a barbiturate). Anesthesia maintenance involved 50-100 $\mu \mathrm{g}$ of Fentanyl given intravenously and $70 \%$ nitrous oxide and $0.5 \%-2.0 \%$ isoflurane (Florane) given in inspired concentration. No patients received benzodiazepines (i.e., Valium or Versed) either preoperatively or intraoperatively. One patient received $60 \mu \mathrm{g}$ of a substitute narcotic (Sufentanyl), in place of Fentanyl, and another received $0.625 \mathrm{mg}$ of droperidol (Inapsine) intraoperatively to control nausea.

\section{Stimulus Administration}

After each patient was fully anesthetized, and before the incision, the prerecorded stimulus list (category-word pairs; homophone sentences) was played through button earphones connected to a portable tape player. The stimulus list was spoken by a female at the rate of one item every $5 \mathrm{sec}$ (sentence or word pair). The same person contacted the patients by phone after surgery to conduct the memory tests.

Each subject heard each sentence or word pair either three times (triples), one time (singles), or zero times (controls). For each set of items (A, B, and C) to be in each presentation condition across subjects, three forms of the stimulus list were required: Form $1-A=$ triples, $B=$ singles, $\mathrm{C}=$ controls; Form $2-\mathrm{A}=$ controls, $\mathrm{B}=$ triples, $\mathrm{C}=$ singles; Form $3-A=$ singles, $B=$ controls, $C=$ triples. The stimulus series presented to the subject was divided into three blocks. Within each block, all six triples (three homophones, three category-word pairs) were presented one time, as were one homophone single and one category single. This resulted in eight trials per block, or 24 stimulus presentations for the complete input list. Patients were assigned to stimulus form on a block-randomized basis: within each successive three patients, one received each of the three forms. Following the taped stimulus list (approximately $2 \mathrm{~min}$ ), the earphones were removed from the patient for the remainder of the surgery.

\section{Memory Test}

Two days following the surgical procedure, each patient was interviewed by phone at home. The subject was initially given an explicit memory assessment, in which he/she was asked to recall anything said or done during the operation. Following this, the implicit memory test was administered. In the first part, 18 individual words were presented, one at a time, and the subject was asked to use each one in a sentence. This list contained the 9 homophone words plus 9 filler (nonhomophonic) words. The sentence-generation task was used rather than a spelling test because the intended meaning of a homophone is not always reflected in its spelling. The second part of the implicit memory test involved category associations. For each of the nine category labels (e.g., "furniture"), the subject produced three members (e.g., "table, chair, sofa").

After the sentence and category-exemplar generation, the interviewer repeated the 18 words in the sentence-generation test and the 27 category responses produced by the patient. For each word, the patient was asked whether he/she recalled hearing it during the operation.

\section{RESULTS}

None of the subjects expressed conscious recollection of experiences during anesthesia, either in a general form or with respect to the specific items on the memory test. Turning to the implicit memory test, for the homophones the average number of low-frequency homophones produced was $1.2,0.9$, and 0.8 for the control, single, and triple conditions, respectively; for category exemplars, the fifth most common response was generated on the average $0.6,1.0$, and 0 times for the control, single, and triple conditions, respectively. Combined across both types of material, the mean production frequency was 0.9 , 1.0 , and 0.4 for the control, single, and triple conditions, respectively. This outcome is illustrated in Figure 1.

An analysis of variance revealed that the overall difference across conditions was statistically significant at a borderline level $[F(2,18)=2.94, p=.078]$. A NewmanKeuls test of pairwise differences indicated a significant difference between the control and triple conditions and between the single and triple conditions but not between the control and single conditions. Thus, it appears that there is evidence of memory under anesthesia. However, this is in the form of response suppression, rather than facilitation.

The reliability of this outcome is supported by examining this difference on a subject-by-subject basis. Comparing the control and triple conditions, 1 subject generated more triples, 5 generated more controls, and 4 generated the same number of both types. Comparing singles and triples, 7 subjects generated more singles, 0 generated more triples, and 3 generated the same number of both types. Again, there appears to be consistent evidence for response suppression with the triples, compared with the single and control conditions.

\section{DISCUSSION}

The results of this experiment indicate that items primed during anesthesia can be suppressed on a postoperative test. With both homo-

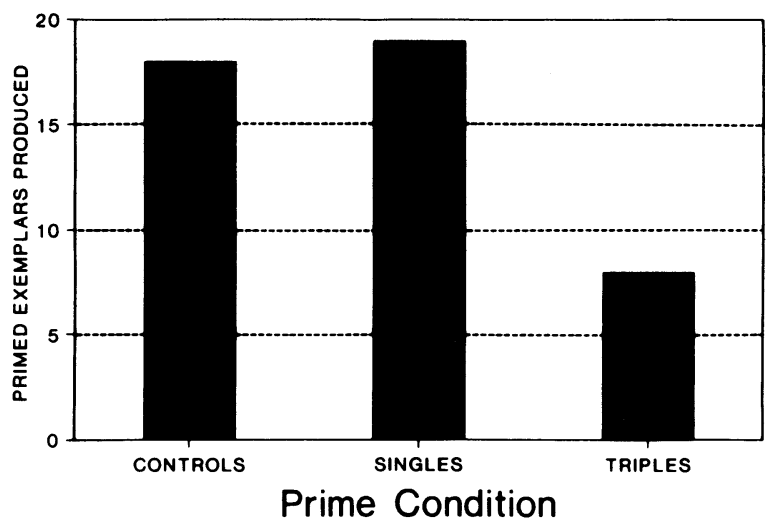

Figure 1. Target-response-generation frequency under control, single, and triple prime conditions. 
phones and category exemplars, items presented three times during anesthesia were produced less often than were control items. This outcome indicates that conditioned suppression of information may occur when the information is presented during specific surgical states. The reason this occurred for the triple items and not for the single items may be that an adequate number of pairings of the verbal material with the aversive experience is required to establish an avoidance response. In subsequent experiments of this type, it would be worthwhile to determine if more repetitions of the words during anesthesia further suppress implicit memory. Number of repetitions will most likely prove to be a complex issue, since one study with 12 homophone repetitions produced no effect (Eich, Reeves, \& Katz, 1985), whereas another study with an average of 67 repetitions of paired word associates (Kihlstrom, Schacter, Cork, Hurt, \& Behr, 1990) yielded a significant priming effect.

The present outcome ostensibly resembles the clinical phenomenon of repression in which ego-threatening communications are actively blocked from access to consciousness (Erdelyi \& Goldberg, 1979; Freud, $1901 / 1960)$. It might be of value to determine whether these responses could be reactivated in these surgical patients during hypnosis (Cheek, 1959; Ewin, 1986). This is a procedure sometimes used in psychoanalytical settings to gain access to supposedly repressed material. It would also be of interest to determine if emotionally charged material is more susceptible to response suppression during anesthesia than is neutral input.

Our outcome may shed some light on why research on memory under anesthesia has produced equivocal results (Bennett, 1988; Trustman et al., 1977). Perhaps both facilitative and inhibitory factors operate during anesthesia states. If the material happens to be experienced at an aversive point in the surgical procedure, retrieval may be subsequently suppressed. However, at other points in the procedure, there may be facilitation. A mixture of facilitation and inhibition may cancel each other out or increase item variance to the point of nullifying any statistically significant effects.

In this investigation, we expected that priming would be reflected in an increased likelihood that subjects would produce low-probability responses following intraoperative exposure (i.e., priming). Because of this, we used materials with relatively low response probabilities to determine if their likelihood would exceed a minimal baseline. In light of the response suppression we noted, a future design might include a mixture of both high- and low-probability responses to reduce the likelihood of obtaining floor effects to items with initially low response probabilities.

Finally, accessing implicit memory may be importantly related to the anesthesia agents used preoperatively, intraoperatively, and postoperatively. For example, benzodiazepines are noteworthy for their amnestic effects and were therefore avoided in the present study. However, narcotic agents (e.g., morphine, Fentanyl, and Demerol) may also produce evidence of amnesia, and the use of Fentanyl in most of the procedures in this study may have influenced retrieval of implicit material under the present conditions.

\section{REFERENCES}

Battig, W. F., Montague, W. E. (1969). Category norms for verbal items in 56 categories: A replication and extension of the Connecticut category norms. Journal of Experimental Psychology Monographs, 80(3, Pt. 2).

Bennetr, H. L. (1988). Perception and memory for events during adequate general anesthesia for surgical operations. In H. M. Pettinati (Ed.), Hypnosis and memory (pp. 193-231). New York: Guilford.

CHEEK, D. B. (1959). Unconscious perception of meaningful sounds during surgical anesthesia as revealed under hypnosis. American Journal of Clinical Hypnosis, 1, 101-103.

Eich, E. (1984). Memory for unattended events: Remembering with and without awareness. Memory \& Cognition, 12, 105-111.

Еich, E., Reeves, J. L., KATZ, R. L. (1985). Anesthesia, amnesia, and the memory/awareness distinction. Anesthesia \& Analgesia, 64, 1143-1148.

ERdelyi, M. H., Goldberg, B. (1979). Let's not sweep repression under the rug: Toward a cognitive psychology of repression. In J. F. Kihlstrom \& F. J. Evans (Eds.), Functional disorders of memory (pp. 355-402). New York: Erlbaum.

EwIN, D. M. (1986). The effect of hypnosis and mental set on major surgery and burns. Psychiatric Annals, 16, 115-118.

FREUD, S. (1960). The psychopathology of everyday life. In J. Strachey (Ed. and Trans.), The standard edition of the complete psychological works of Sigmund Freud (Vol. 6). London: Hogarth. (Original work published 1901)

Graf, P., \& SChacter, D. L. (1985). Implicit and explicit memory for new associations in normal and amnesic subjects. Journal of Experimental Psychology: Leaming, Memory, \& Cognition, 11, 501-518.

Kinlstrom, J. F., SCHACTER, D. L. (1990). Anaesthesia, amnesia, and the cognitive unconscious. In B. Bonke, W. Fitch, \& K. Millar (Eds.), Memory and awareness in anesthesia (pp. 21-44). Amsterdam: Swets \& Zeitlinger.

Kinlstrom, J. F., Schacter, D. L., Cork, R. C., Hurt, C. A., \& BEHR, S. E. (1990). Implicit and explicit memory following surgical anesthesia. Psychological Science, 1, 303-306.

SCHACTER, D. L. (1987). Implicit memory: History and current status. Journal of Experimental Psychology: Learning, Memory, \& Cognition, 13, 501-518.

Trustman, R., Dubovsky, S., \& Titley, R. (1977). Auditory perception during general anesthesia: Myth or fact? International Journal of Clinical \& Experimental Hypnosis, 25, 88-105.

TUlving, E. (1985). How many memory systems are there? American Psychologist, 40, 385-398.

Tulving, E., Schacter, D. L. (1990). Priming and human memory systems. Science, 247, 301-306.

(Manuscript received January 31, 1992.) 